\title{
A Debate on Literature as a Teaching Material in FLT
}

\author{
Ferdows Aghagolzadeh \\ Department of General Linguistics, Faculty of Humanities, Tarbiat Modares University, Tehran, Iran \\ Farzaneh Tajabadi (Corresponding Author) \\ Department of General linguistics, Faculty of Humanities, Tarbiat Modares University, Tehran, Iran \\ Email: farzaneh.tajabadi@modares.ac.ir
}

\begin{abstract}
Teaching materials play an important role in most foreign language teaching programs. The number of studies on this subject bears ample testimony to the significance given by scholars in this regard. This article is a review on some reasons that scholars propose for the use of literature as a language teaching material in foreign language (FL) classes and compares favors and disfavors ideas in this regard. Among a welter of reasons which have been proffered by a variety of authors and can be considered as the merits of literature in FLT, this study focuses on authenticity, cultural/incultural understanding, critical thinking and language skills and expand them further. This paper argues that teaching literature enhances students' cultural understanding, facilitates critical thinking and improves language skills and all of these advantages caused by the authentic nature of literature.
\end{abstract}

Index Terms - literature, FLT, authenticity, critical thinking, cultural awareness, language skills

\section{INTRODUCTION}

Teaching materials play an important role in FL teaching programs. For this reason, teachers rely on a different range of materials to support their teaching and their students learning. In this regard, Seniro (2005) says "we need to have a clear pedagogic goal in mind: what precisely we want our students to learn from these materials" (p.71). It is one of the self-evident things that as a teacher of a Foreign Language, our main concern is to help learners acquire communicative competence. Savvidou (2004) points that communicative competence is more than acquiring mastery of structure and form, it also involves acquiring the ability to interpret discourse in all its social and cultural contexts. In this direction and in order to reach this lofty goal, Howard \& Major (2004) propose ten guidelines for preparing teaching materials. They argue that these materials should:

1- Be contextualized

2- Stimulate interaction and be generative in terms of language.

3-Encourage learners to develop learning skills and strategies.

4-Allow for a focus on form as well as function.

5- Offer opportunities for integrated language use.

6- Be authentic.

7-Link to each other to develop a progression of skills, understanding and language items

8-Be attractive

9-Have appropriate instruction

10- Be flexible

According to these different criteria, the main question is that if literature can be used as an appropriate material and if it can satisfy these factors? In this paper we try to show that literature is in agreement with these yardsticks.

\section{StATEMENT OF Problem}

From time to time the need or value of teaching literature in the language class, as a teaching material, has been questioned. Using of literature to teach second/foreign languages can be traced back to over one century ago, but in recent times (the middle of the 1980s) a renewed interest has emerged in the teaching of literature in the language class. This can be confirmed by seeing so many publications heralding the coming back of literature in language classes. Maley (2001) (cited in Khatib et al., 2011) argues that this attitude toward literature is due to a paucity of empirical research confirming the significance of literary input for language class. Notwithstanding the few controversial points regarding whether literature can be used to enhance the efficiency of language learning programs, the relevant literature abounds with the reasons why literary exploration can be beneficial in the language classroom. Researchers who advocate the use of literature to teach SL/FL list several benefits of it. For example, Lazar (1993) (cited in Ubukawa \& Miyazaki, 2003) proposes six purposes or reasons for using literature in the language classroom as motivating material, 
access to cultural background, encouraging language acquisition, expanding students' language awareness, developing students' interpretative abilities, and educating the whole person. Van (2009) also (cited in Bagherkazemi \& Alemi, 2010) counts some advantages of using literature in the FL classroom as below:

1- It provides meaningful contexts;

2- It involves a profound range of vocabulary, dialogues and prose;

3- It appeals to imagination and enhances creativity;

4- It develops cultural awareness;

5- It encourages critical thinking;

6- It is in line with CLT (Communicative Language Teaching) principles.

In sum, motivation, authenticity, cultural/ intercultural awareness and globalization, intensive/ extensive reading practice, sociolinguistic/pragmatic knowledge, grammar and vocabulary knowledge, language skills, emotional intelligence and critical thinking are the payoffs' list of using literature in FL/SL classes (Khatib et al., 2011). However, some of these justifications or benefits are the subject of debate among scholars and some experts have posited the possible potholes literature might cause in language class. However, Savvidou (2004) believes that the reasons why few experts often consider literature inappropriate to the language classroom may be found in the common beliefs held about literature and literary language and these views reflect the historic separation between the study of language and the study of literature, which has led to the limited role of literature in the language classroom. Since scholars are not unanimous about this subject, so the purpose of this paper is to compare the different viewpoints (favors and disfavors), to reach a rational conclusion about using literature as an appropriate teaching material in FL class.

\section{IDEAS AND DISCUSSION}

Among a welter of reasons which have been proffered by a variety of authors, this study focuses on authenticity, cultural/incultural understanding, critical thinking and language skills and attempts to expand them further.

\section{A. Authenticity}

Authenticity is a criterion considered highly essential in the current literature in FLT (Khatib, et.al., 2011). A brief look at FL textbook topic contents, reveal that they are fictions in a variety of ways. In other words, they are often unreal in the sense of irrelevant to the learners. The artificial nature of the language and structures used, make them very alike anything that the learner will encounter in the real world and very often they don't reflect how the language is really used. Berado (2006) states: “ one of the main reason for using authentic materials in the classroom is once outside the safe, controlled language learning environment, the learner will not encounter the artificial language of classroom but the real world and language how it is really used". According to Wallace (1992), authentic texts are "reallife texts, not written for pedagogic purposes" (p.145). Peacock (1997) says the purpose of producing this material is to fulfill some social purpose in the language community. Berado (2006) writes the sources of authentic materials that can be used in the FL class are infinite and proposes four factors worth taking into consideration when choosing authentic material for the classroom. These factors are: suitability of content, exploitability, readability and presentation. He believes that the main advantages of using authentic materials in the classroom include:

1- Having a positive effect on student motivation;

2- Giving authentic cultural information;

3- Exposing students to real language;

4- Relating more closely to students' needs;

5- Supporting a more creative approach to teaching.

Cruz (2010) believe that literature as aesthetic recreation can be considered a much more "authentic" source and can inspire more authority in the use and enrichment of language. He says "literature can be regarded as a rich source of authentic material, because it conveys two features in its written text: one is 'language in use', that is, the employment of linguistics by those who have mastered it into a fashion intended for native speakers; the second is an aesthetic representation of the spoken language, which is meant to recover or represent language within a certain cultural context". Literature as the authentic material, imparts the diverse forms and functions of written language (Hadaway, 2002). These are what make us excited and willing to use authentic materials in EFL class, but opponents believe that while using them, it is inevitable that we face some problems. Martinez (2002) (cited in Berardo, 2006) writes the negative aspects of authentic materials are that they can be too culturally biased, often a good knowledge of cultural background is required when reading, as well as too many structures being mixed, causing lower levels problems when decoding the texts.

If we summarize the focal points of this discussion, we can say that arguably more important than the provision of authentic texts, is authenticity in terms of the tasks which learners are required to perform with them. From what was said we can conclude that the use of literary text as an authentic material, from language teaching point of view, will be useful because these texts show how language works in contexts. Furthermore, they show how language should be used in which condition and situation.

\section{B. Cultural/Incultural Understanding}


The debate about whether or not to include culture in a language class is long past. A few words are necessary concerning what we mean by 'culture'. This is the same sense as in Goodenough's well-known definition: 'a society's culture consists of whatever it is one has to know or believe in order to operate in a manner acceptable to its members, and to do so in any role that they accept for any one of themselves' (Wardhaugh, 1990, p.211). Sapir in his book Language, acknowledged the close relationship between language and culture, maintaining that they were inextricably related so that you could not understand or appreciate the one without knowledge of the other (ibid. 212). Cruz (2010) quotes from Kramsch (1998) that it is important to be aware that culture in language learning is not an expendable fifth skill; it is present within writing, reading, listening and speaking. In order to teach culture systematically, teachers should set clear and achievable goals. The main aim of cultural teaching, as recognized by most scholars today, is to develop student's intercultural understanding and help them with intercultural communication. For the latter, learners need cultural knowledge, cultural awareness and a set of skills, which constitute the learner's intercultural competence. Despite the recognition of the importance of culture in language class, the teaching of it has still remained limited. One of the main reasons for that is the issue of designing a cultural syllabus and choosing appropriate materials. If we accept that language production always occurs within a broad or narrow context of culture, then all subject content and associated learning materials must also have a cultural base that encompasses elements of an affective, linguistic spectrum. Most of researchers (Kramsch, 1998, Parkinson \& Reid Thomas, 2000, Lazar, 2005, Van, 2009, Tayebipour, 2009) argue that literature is a good material for this purpose and teaching literature can help learners to increase their knowledge of another (target) culture. Sell (2005) writes: "in an age when multiculturalism has installed itself as the shibboleth of societies and the words interculturality and transculturality circulate as buzzwords in academia, it is unsurprising that perhaps the foremost defense of literature teaching in the FL class is that it fosters awareness of cultural, ethnic, religious, racial etc. diversity and sensitizes the young to contrasting perspectives, concepts and world views, such sensitivity being vital to life in community in the global village." According to Maley(1989)(quoted by Khatib, et.al., 2011), literature deals with universal concepts such as love, hatred, death, nature, etc. that are common to all languages and cultures. The similarity and even differences between cultures and languages can further our understanding of the whole world. Sell (2005) argues that "teaching literature provides learners with a truly cultural competence, equipping them with culturally-apposite pragmatic and socio-psychological components around which to build effective identities which will enable their socialization in the target culture and enhance the effectiveness with which they participate in that culture". So it is hard to ignore the cultural benefits of studying literature, since literature mirrors national culture. However, there are some arguments against this view. For example, McKay (1982) contends "it is easy to view any attention to literature as unnecessary" (p.529). He states that literature is highly culturally charged, hence its conceptual difficulty and its hindrance, rather than facilitation, of learning the target language (cited in Bagherkazemi and Alemi, 2010).

\section{Critical Thinking Skill}

The importance being accorded to critical thinking is now a worldwide phenomenon. Critical thinking has been given importance and discussed in educational settings in particular for the last two decades. The intellectual roots of critical thinking are as ancient as its etymology, traceable, ultimately, to the teaching practice and vision of Socrates 2500 years ago. Glaser defines critical thinking as "(1) an attitude of being disposed to consider in a thoughtful way the problems and subjects that come within the range of one's experience; (2) knowledge of the methods of local inquiry and reasoning; and (3) some skills in applying those methods" (Fisher, 2001:3). Haskins (2006) defines as "critical thinking is more than thinking logically or analytically; it also means thinking rationally or objectively" (p.2). Then he (ibid. p.3) listed 5 steps of the features that would be present in those thinking critically (Fig.1).

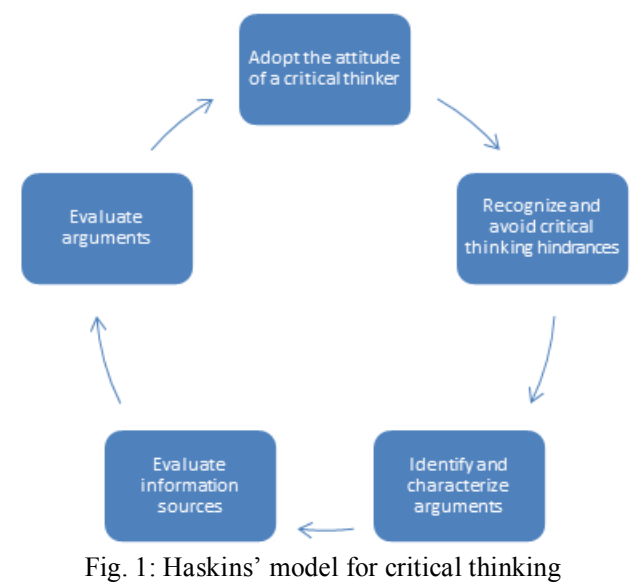

Lipman (cited in Juuso, 2007, p.70) also count four features for critical thinking. He believes that critical thinking is a kind of thinking that (1) facilitates judgment because it (2) relies on criteria, (3) is selfcorrective, and (4) is sensitive to context. 
The tools and resources of the critical thinking have been vastly increased in virtue of the history of critical thought. One important thing that can trigger critical thinking is an authentic text. As noted before literature is inherently authentic so it can enhance critical thinking among language learners (Gajdusek \& van Dommelen, 1993; Ghosn, 2002; Hadaway, 2002; Lazar, 2005; Van, 2009). Ghosn (2002) says that literature can change the attitudes of the learners. Nafisah (2006) writes: "as literary texts are often rich in multiple levels of meanings, the readers, in this case FL learners should be able to uncover the implied meanings of a particular text. For example, in a poem, a word may have figurative meanings that should be interpreted by the readers. The attempt to disclose the real meaning of the word gives the students the opportunity to see the meaning from different angles. This activity helps students to develop their critical thinking skills because they have to be able to produce sound argument on their choice of interpretation". Langer (1997) noted that "literature permits students to reflect on their lives, learning, and language. Literature can open horizons of possibility, allowing students to question, interpret, connect, and explore" (p.607). Today, critical thinking is the cornerstone of education particularly at advanced levels of education, in fact literature offers a natural medium through which students can be introduced to the type of thinking and reasoning expected in academic classes (Khatib, et.al., 2011). These include looking for main points and supporting details; comparing and contrasting; looking for cause-effect relationships; evaluating evidence, and becoming familiar with the type of language needed to express the thinking (Ghosn, 2002).Ultimately, unlike textbook readers, literature readers are able to choose and judge any reading materials to function them better. In fact since literature presents problems faced by human beings, it evokes critical discussion. In doing so, students are expected to be aware of not only how to use FL correctly and appropriately, but also engage their mind critically (Nafisah, 2006).

\section{Language Skills}

Today, language skills (reading, writing, speaking \& listening) are high priorities. Some scholars (stern, 1991; Belcher \& Hirvela, 2000; Erkaya, 2005; Van, 2009) believe that literature can provide a medium through which these needs can be addressed and literature can improve language skills. Povey (1972) argues that "literature will increase all language skills because literature will extend linguistic knowledge" (p.18). Turker (1991) thinks that literature with its extensive and connotative vocabulary and also its complex syntax, can expand all language skills. Oster (1989) writes "literature helps students to write more creatively" (p.85). Murdoch (2002) believe that if literature text selected and exploited appropriately, it can provide quality text content which will greatly enhance ELT courses for learners. Ghosn (2002) also says that through the medium of literature we can provide FL learners with language experiences that will not only motivate and foster oral language, but also deepen their awareness of the target language in its written form. In other words, it provides models for their own writing. He also argues that because literature presents natural language, language at its finest, thus can foster vocabulary development in context. Cruz (2010) conveys that a literary text provides students with a much clearer idea about the syntactic structure of a written text and to what extent written language differs from spoken language. He continues that by getting used to the formation and function of sentences, to the structure of a paragraph, a section or a chapter, their writing skill improve and their speech skill can gain eloquence. Berardo (2006) also believes that literature as an authentic material can improve language skills especially reading. From his point of view, reading is considered to be an ongoing interaction, going beyond the physical context of the text looking for meaning as well as processing information.

The above subject is another point of controversy which has been pointed out by some experts. McKay (1982) believes literature's structural complexity, and unique and sometimes nonstandard use of language precludes the teaching of grammar which is one of the main goals of language teachers (cited in Bagherkazemi and Alemi, 2010). Difficult language, complex language structure and unneeded vocabulary are the problems that Richards (2001) counts for authentic material like literature. Berardo (2006) notes that the biggest problem with authentic material is that if the wrong type of text is chosen, the vocabulary may not be relevant to the learner's needs and too many structures can create difficulty.

In sum, Savvidou (2004) summarizes the reasons that few experts argues against teaching literature as below:

1-literature is particularly complex and inaccessible for the foreign language learner and can even be detrimental to the process of language learning.

2- It is difficult to imagine teaching the stylistic features of literary discourse to learners who have a less than sophisticated grasp of the basic mechanics of foreign language.

3- The creative use of language in poetry and prose often deviates from the conventions and rules which govern standard, non-literary discourse, as in the case of poetry where grammar and lexis may be manipulated to serve orthographic or phonological features of the language.

4- The reader requires greater effort to interpret literary texts since meaning is detached from the reader's immediate social context. The result is that the reader's "interpretative procedures" may become confused and overloaded.

To bring to a conclusion, we can say that comparison more arguments support the relevance of using literature to the teaching of a foreign language and use of literary texts can be a powerful pedagogic tool. It seems that all advantaged mentioned above, result from authentic character of literature because both opponents and those in favour refer to this factor to prove their claim.

\section{RESULTS}


Taking heed of all disfavors, in conclusion, we would defend the use of literature in the FL class on the basis of arguments set out above. Integrating literature in FLT paves the way for equipping students with a number of skills. Most important of these skills include: cultural awareness; development of critical thinking; analytical skills; language skills. In other words, an integrated approach to the use of literature in the language classroom offers foreign language learners the opportunity to develop not only their linguistic and communicative skills but their knowledge about language in all its discourse types. It must be take into consideration that those features which are addressed as literature's disadvantages in the EFL, i.e. its cultural load, structural complexity and non-normative use of language, are exactly what can be employed to enrich language teaching and learning experiences. Although, it needs to be reiterated that the current consensus of opinion regarding the integration of literature in language programs, is overwhelming, and by far exceeds the points of controversy.

\section{REFERENCES}

[1] Bagherkazemi, M. \& Alemi, M. (2010). Literature in the EFL/ ESL classroom: consensus and controversy. LiBRI. 1, 30-48.

[2] Belcher, D. \& Hirvela, A. (2000). Literature and L2 composition: revisiting the debate. Second language writing 9.1, 21-39.

[3] Berardo, S.A. (2006). The use of authentic materials in the teaching of reading. The reading matrix 6. 2, 60-69.

[4] Cruz, J.H.R. (2010). The role of literature and culture in English language teaching. http://www.relinguistica.aza.uam.mx/no007/no07 art09.html (accessed 8/11/2011).

[5] Erkaya, O.R. (2005). Benefits of using short stories in the EFL context. Asian EFL 8, 1-13.

[6] Fisher, A. (2001). Critical thinking: An introduction. UK: Cambridge University Press.

[7] Gajdusek, L., \& Van Dommelen, D. (1993). Literature and critical thinking in the composition classroom. In J. Carson \& I. Leki (eds.), Reading in the composition classroom: Second language perspectives. Boston: Heinle \& Heinle, 197-215.

[8] Ghosn, I.K. (2002). Four good reasons to use literature in primary school ELT. ELT 56(2),172-179.

[9] Hadaway, N. (2002). Literature-based instruction with English language learners, K-12. Boston: Allyn and Bacon.

[10] Howard, J. \& Major, J. (2004). Guidelines for designing effective English language teaching materials. http://www.paaljapan.org/resources/proceedings/PAAL9/pdf/Howard.pdf (accessed 5/9/2011).

[11] Juuso, H. (2007). Child, Philosophy and Education. Oulu: Oulu University Press.

[12] Khatib, M., Rezaei, S., \& Derakhshan, A. (2011). Literature in EFL/ESL classroom. ELT 4.1, 201- 208.

[13] Kramsch, C. (1998). Language and culture. Oxford: Oxford University.

[14] Langer, J. (1997). Literacy acquisition through literature. Adolescent and adult literacy 40, 602-614.

[15] Lazar, J. (2005). Literature and language teaching: A guide for teachers and trainers. Cambridge: Cambridge University Press.

[16] McKay, S. (1982). Literature in the ESL classroom. TESOL Quarterly 16.4, 529-526.

[17] Malay, A. (1989). Down from the pedestal: literature as resource. In R. Carter, R. Walker \& C. Brumfit (eds.), Literature and the learner: methodological approaches. Modern English Publications and the British Counsel, 1-9.

[18] Murdoch, G. (2002). Exploiting well-known short stories for language skills development. IATEFL LCS SIG Newsletter 23, 917.

[19] Nafisah, N. (2006). Literature in ELT setting: Paving the way for critical students. www.ebookbrowse.com/literature-in-ELT-setting-pdf-d124842092 (accessed 25/7/2011).

[20] Oster, J. (1989). Seeing with different eyes: Another view of literature in the ESL class. TESOL Quarterly 23.1, 85-103.

[21] Parkinson, B. \& Reid Thomas, H. (2000). Teaching literature in a second language. Edinburgh: Edinburgh University Press.

[22] Peacock, m. (1997). The effect of authentic materials on the motivation of EFL learners. ELT 51, 2-11.

[23] Povey, J. (1972). Literature in TESL programs: the language and the culture. In H. Allen \& R. Campbel (eds.), Teaching English as a second language. New York: Mc.Graw Hill.

[24] Richard, J.C. (2001). Curriculum development in language teaching. Cambridge: C.P.U.

[25] Savvidou, C. (2004). An Integrated Approach to Teaching Literature in the EFL Classroom. The Internet TESL Journal 6.12.

[26] Sell, J. (2005). Why teach literature in the foreign language classroom?. Encuentro15, 86-93.

[27] Senior, R. (2005). Authentic responses to authentic materials. www.etprofessional.com. English teaching professional. Issue 38. 71. (accessed 15/6/2011).

[28] Stern, S.L. (1991). An integrated approach to literature ESL/ EFL. In M. Celce- Murcia (ed.), Teaching English as a second or foreign language $\left(2^{\text {nd }}\right.$ ed). New York: Newbury House, 328-346.

[29] Tayebipour, F. (2009). In defence of teaching literature to EFL students in the era of globalization. In L.J. Zhang, R. Rubdy \& R. Alsagoff (eds.), Englishes and literatures- in-English in a globalized world: proceeding of the 13th international conference on English in southeast Asia. Singapore: National Institute of Education, Nanyang Technological University, 213-219.

[30] Turker, F. (1991). Using literature in language teaching. Hacettepe Universitesi Egitim facultesi dergisi 6, 299-305.

[31] Ubukawa, E. \& Miyazaki Ishida, Y. (2003). Using Children's Literature in the EFL Reading Classroom. Maebashi 3, 57-72.

[32] Van, T.T.M. (2009). The relevance of literary analysis to teaching literature in the EFL classroom. English Teaching Forum 3: 2-9.

[33] Wallace, C. (1992). Reading oxford. New York: Oxford University Press.

[34] Wardhaugh, R. (1990). An introduction to sociolinguistics. Oxford and Cambridge: Basil Blackwell. 


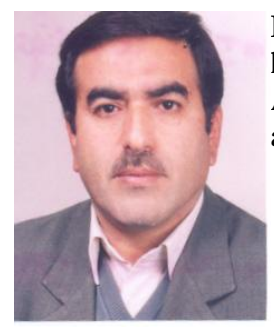

Ferdows Aghagolzadeh is Associate Professor of Linguistics at Tarbiat Modares University (Tehran, Iran). He holds an M.A. and a Ph.D. in Linguistics from Tarbiat Modares University and a B.A. in English Literature from Allameh Tabataba'i University (Iran, Tehran). His main areas of interest include applied linguistics, discourse analysis \& CDA. He has published some books and articles in these areas.

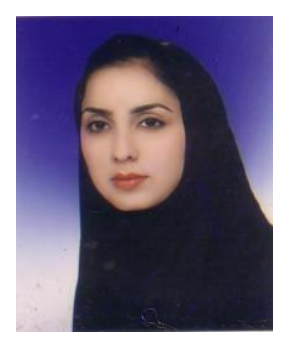

Farzaneh Tajabadi is a Ph.D. candidate in General Linguistics at Tarbiat Modares University (Iran, Tehran). She holds a B.A. in Translation Studies from Allameh Tabataba'i University (Iran, Tehran, 2005) and an MA in General Linguistics from University of Tehran (Iran, Tehran, 2008). Her interests include sociolinguistics, morphology \& phonology and has published and presented papers in these areas. 